\title{
PAISAGEM E PERCEPÇÃO SOCIOAMBIENTAL EM ÁREAS DE VÁRZEAS URBANIZADAS, BELÉM-PARÁ
}

\author{
Viviane Corrêa Santos ${ }^{1}$ \\ Márcia Aparecida da Silva Pimentel ${ }^{2}$ \\ Carla Cristina de Azevedo Sadeck ${ }^{3}$ \\ Aline Maria Meiguins de Lima $^{4}$
}

\begin{abstract}
RESUMO
As várzeas são áreas importantes no contexto da paisagem amazônica. A sua ocupação remete à história dos primeiros grupos humanos na região. O processo de ocupação urbana, na sua história mais recente, tem modificado a dinâmica dessa unidade especialmente no seu sistema hidrológico, que passa a se readequar aos padrões de urbanização. O objetivo deste trabalho é discutir as propostas para o ordenamento urbano em áreas de várzea no município de Belém (PA), a partir da percepção das comunidades sobre o processo de reconstrução da paisagem. Os procedimentos metodológicos utilizados referiram-se inicialmente à revisão de literatura sobre os conceitos e materiais técnicos utilizados. Posteriormente, foram aplicados questionários, com questões abertas e fechadas, para os moradores que residem nessas áreas. Os resultados forneceram informações para compilação de material cartográfico e enfatizaram a percepção das questões sociais e ambientais apresentadas pelas comunidades. Para discussão dos dados foi utilizada a análise hierárquica desenvolvida no software Expert Choice. Como conclusão, considera-se que os instrumentos técnicos relevantes para demonstrar a relação entre as respostas obtidas e levou à constatação de que, geralmente, os planejadores urbanos ainda persistem em propor projetos sociais que desconsideram a diversidade cultural dos moradores. Ressalta-se que percepção da paisagem expressa todo um significado social que só é sentido por aqueles que a vivem e tem sua história como herança de vida. Assim, as ações de gestão e planejamento devem ser incorporadas nesta lógica, devendo-se questionar até que ponto a manutenção de determinadas condições não amplia a vulnerabilidade socioambiental de uma comunidade.
\end{abstract}

Palavras-chave: Espaço urbano. Bacias hidrográficas. vulnerabilidade.

\begin{abstract}
The floodplains are important areas in the context of the Amazonian landscape. The urban occupation process, in its most recent history, has modified the dynamics of this unit especially in its hydrological system, which is now adapted to urbanization patterns. The bjective of this work is to discuss the proposals for urban planning in floodplain areas in the city of Belém (PA), based on the communities' perception of the process of landscape reconstruction. The methodological procedures used initially referred to the literature review on the concepts and technical materials used. Subsequently, questionnaires, with open and closed questions, were applied to residents living in these áreas. The results provided information for the compilation of cartographic material and emphasized the perception of social and environmental issues presented by the communities. For discussion of the data, the hierarchical analysis developed in the Expert Choice software was used. As a conclusion, it is

\footnotetext{
1 Professora Mestre em Geografia Física da Universidade do Estado do Pará - UEPA E-mail: Viviane.santos@gmail.com

${ }^{2}$ Pós-Doutora em Geografia da Universidade Federal do Pará - UFPA. E-mail: mapimentel@ufpa.br

3 Professora Mestre em Ciências Ambientais pela Universidade Federal do Pará - UFPA. E- mail: carla.sadeck@gmail.com

${ }^{4}$ Doutora em Desenvolvimento Socioambiental pelo Núcleo de Altos Estudos Amazônicos da Universidade Federal do Pará - UFPA. E-mail: alinemeiguins@gmail.com
} 
considered that the technical instruments were of significant relevance to demonstrate the relationship between the answers obtained and led to the finding that, generally, urban planners still persist in proposing social projects that disregard the cultural diversity of the residents. It is emphasized that perception of the landscape expresses a whole social meaning that is only felt by those who live it and has its history as inheritance of life. Thus, management and planning actions should be incorporated into this logic, and it should be asked to what extent the maintenance of certain conditions does not increase the socio-environmental vulnerability of a community.

Keywords: Urban space. Watersheds. Environmental.

\section{INTRODUÇÃO}

A paisagem pode ser entendida, segundo Mezzomo (2010, p. 30), "a partir da interação dos componentes naturais com as ações antrópicas, [...]". Da mesma forma que "O conceito de paisagem abrange dinâmicas e conexões estabelecidas entre os seguintes elementos: as relações culturais, o apego ao lugar, às marcas da resistência, as formas de sobrevivência, entre outros." (SANTOS, 2012, p. 30). Ao se relacionar "[...] a paisagem a partir da percepção do espaço vivido-concebido, há de se entender que a paisagem é um elemento componente da natureza, mas também é constantemente transformado de acordo com as relações econômicas e culturais dos diferentes grupos sociais que moldam constantemente a construção da forma, do conteúdo e do processo dessas paisagens para melhor se adequar a seus traços culturais" (SANTOS, 2012, p. 33).

Ainda em meio a essa contribuição, "a percepção, em especial a ambiental, foi desenvolvida a partir da perspectiva de que os atributos do meio ambiente sejam eles natural ou construído, acabam tendo influência sobre o processo perceptivo dos sujeitos, possibilitando o reconhecimento da qualidade ambiental e, por conseguinte a formação da mesma imagem por vários sujeitos desses grupos” (SANTOS, 2012, p. 41).

Para Vitte (2009), a qualidade de vida está ligada também a manifestações e construções históricas. E o lugar é pensado como o suporte da almejada qualidade de vida, num sentido mais amplo que chega a abarcar elementos econômicos, sociais, políticos, culturais, ambientais. Que em conjunto, vem a participar das construções das identidades e do sentido de pertencimento da comunidade.

O fato de se considerar a bacia hidrográfica como unidade de gestão do território, implica na necessidade de implantar o controle de ocupação do mesmo, em especial das áreas de várzea; uma vez que, a bacia hidrográfica pode contribuir como um instrumento de planejamento de ações urbanas de controle e contenção de fenômenos que acontecem nas cidades brasileiras (MERWADE et al, 2008; GORAYEB et al, 2009). 
Ter a bacia hidrográfica como uma unidade de gestão seria uma tentativa de amenizar os prejuízos socioambientais e econômicos, de criar uma relação mais sustentável entre o sistema fluvial e o urbano, e assim evitar que as enchentes e inundações tragam sérias consequências em momentos de extremos hidrológicos ou que a urbanização gere a degradação hídrica em temos de qualidade e quantidade (CARNEIRO et al, 2010).

A ocupação de ambientes naturalmente perigosos é uma situação associada às áreas de várzea. A ameaça está diretamente vinculada às condições naturais e antrópicas ligadas a precariedade das moradias, o que favorece uma situação de vulnerabilidade. Esta é caracterizada por um conjunto de fatores sociais, culturais, educativos que determina se uma comunidade está mais ou menos exposta a um evento, sejam por suas características ou por sua capacidade de responder e de se recuperar de tal evento (KENYON, 2007; SAMPAIO et al, 2012).

O intenso processo de urbanização associado ao uso e ocupação das planícies naturais de inundação, a obstrução dos cursos d'água por obras hidráulicas inadequadas e pelo lançamento de lixo, a impermeabilização dos solos urbanos, dentre outras, são ações que contribuem para agravar o impacto socioambiental e econômico (PIMENTEL et al , 2012; TARGA et al, 2012). Com relação às degradações socioambientais, Ribeiro (2008) demonstra que essas ações são resultado de alterações feitas pelas sociedades à natureza, independentemente de seu desenvolvimento.

Em relação à cidade de Belém - PA é praticamente impossível não ter percebido que no decorrer do tempo, particularmente entre 1990 e 2012, as áreas centrais passaram por um processo de modernização, que ainda hoje vem modificando a paisagem de Belém e de outros municípios da Região Metropolitana.

No processo histórico de urbanização de Belém, pode-se ter como marco a expansão da ocupação das várzeas a década de 1950, momento este a partir do qual houve uma intensa expansão horizontal para além de uma vasta extensão de terras, denominada de "Cinturão Institucional". A ocupação em áreas inadequadas foi mais uma vez resultado de situações como: crise econômica, desemprego, crescimento demográfico intenso, somado ao baixo poder de investimento do setor público (MATOS et al, 2011; PIMENTEL et al, 2012).

A urbanização na Amazônia tem na rede hidrográfica um forte aspecto, que teve de lidar com a convivência com a água, sendo esta a lógica da ocupação da periferia (áreas tidas como "residuais" ou de "expansão" para os interesses do mercado imobiliário) derivada de um tipo de ocupação precária marcada pela pobreza urbana, bem como, pelo impacto sobre áreas de proteção ambiental em geral (XIMENES, 2007). 
Nessa discussão, insere-se uma abordagem relacionada aos comportamentos e relações entre o humano e o lugar habitado, que dizem respeito à familiaridade ou apego ao lugar (topofilia) ou sua aversão (topofobia) (SILVA, 2002; TUAN, 2012; SILVA et al, 2014). Para Rodrigues et al (2012) a percepção ambiental é inerente a cada indivíduo, que percebe, reage e responde as ações exercidas sobre o meio, sendo capaz de fornecer subsídios ao processo de gestão e formulação de políticas públicas. Neste contexto, objetivou-se contribuir para o tratamento da subjetividade da percepção social, tendo como estudo de caso o processo de reconstrução da paisagem de várzea em uma área urbanizada localizada na margem direita da baía de Guajará, no município de Belém-PA.

\section{MATERIAL E MÉTODOS}

A cidade de Belém localiza-se numa península cercada ao sul pelo rio Guamá, a oeste pela baía do Guajará, ao norte pelo furo do Maguari e a leste se limita com o município de Ananindeua. As características geomorfológicas mostram um relevo de baixo a levemente ondulado, situado entre terrenos secos e alagados. Santos (2012) analisa que Belém era composta territorialmente por uma área de planície (várzea), que alcançava em torno de $40 \%$ de seu território (Mapa 1).

Mapa 1. Espacialização da área de várzea de Belém-PA

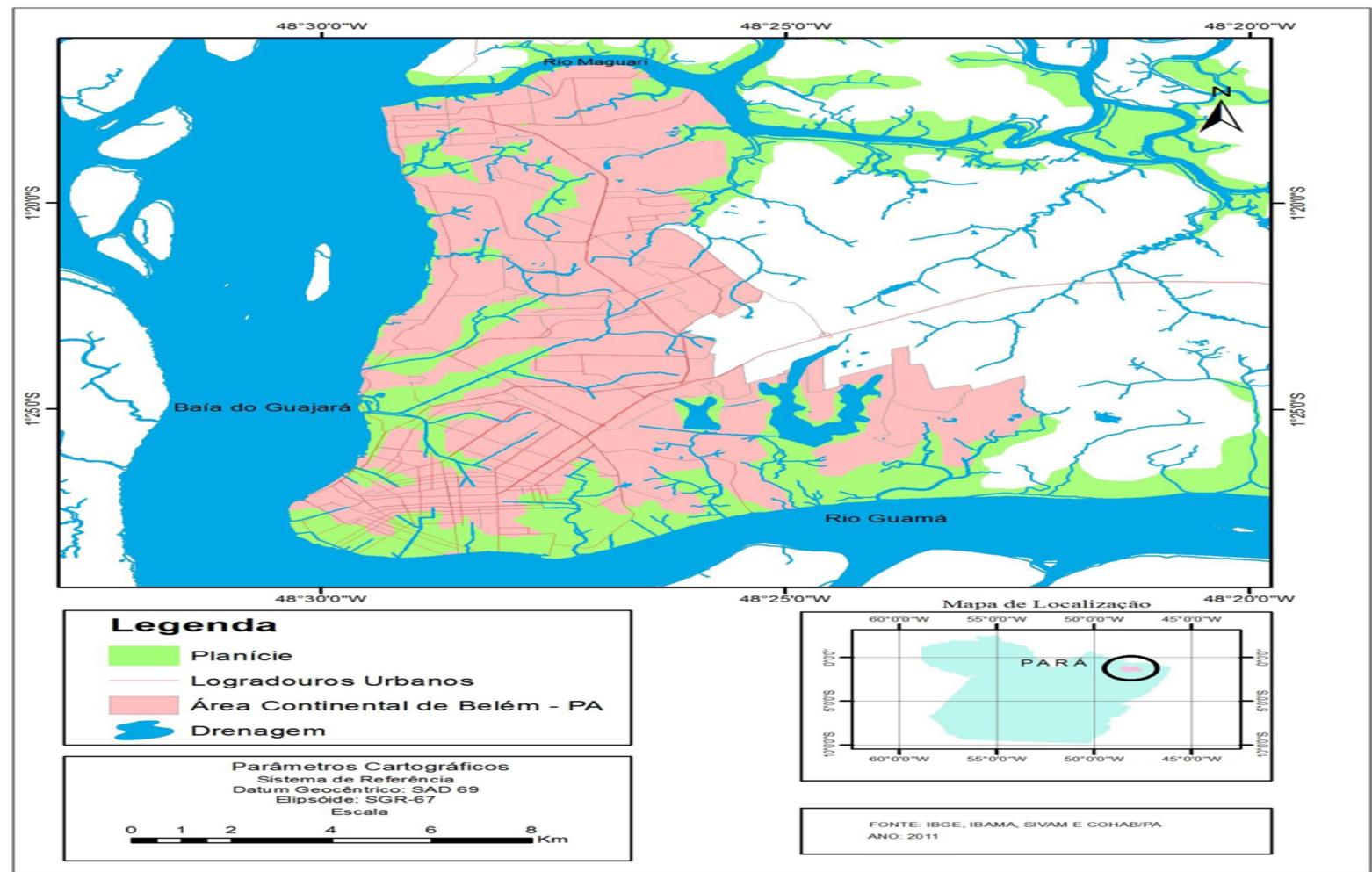

Fonte: Santos, 2012. 
A área de estudo, localmente conhecida como Vila da Barca, localiza-se no bairro do Telégrafo sem Fio, o qual está inserido na bacia hidrográfica do Una. (Mapa 2).

Mapa 2. Bacias hidrográficas de Belém-PA

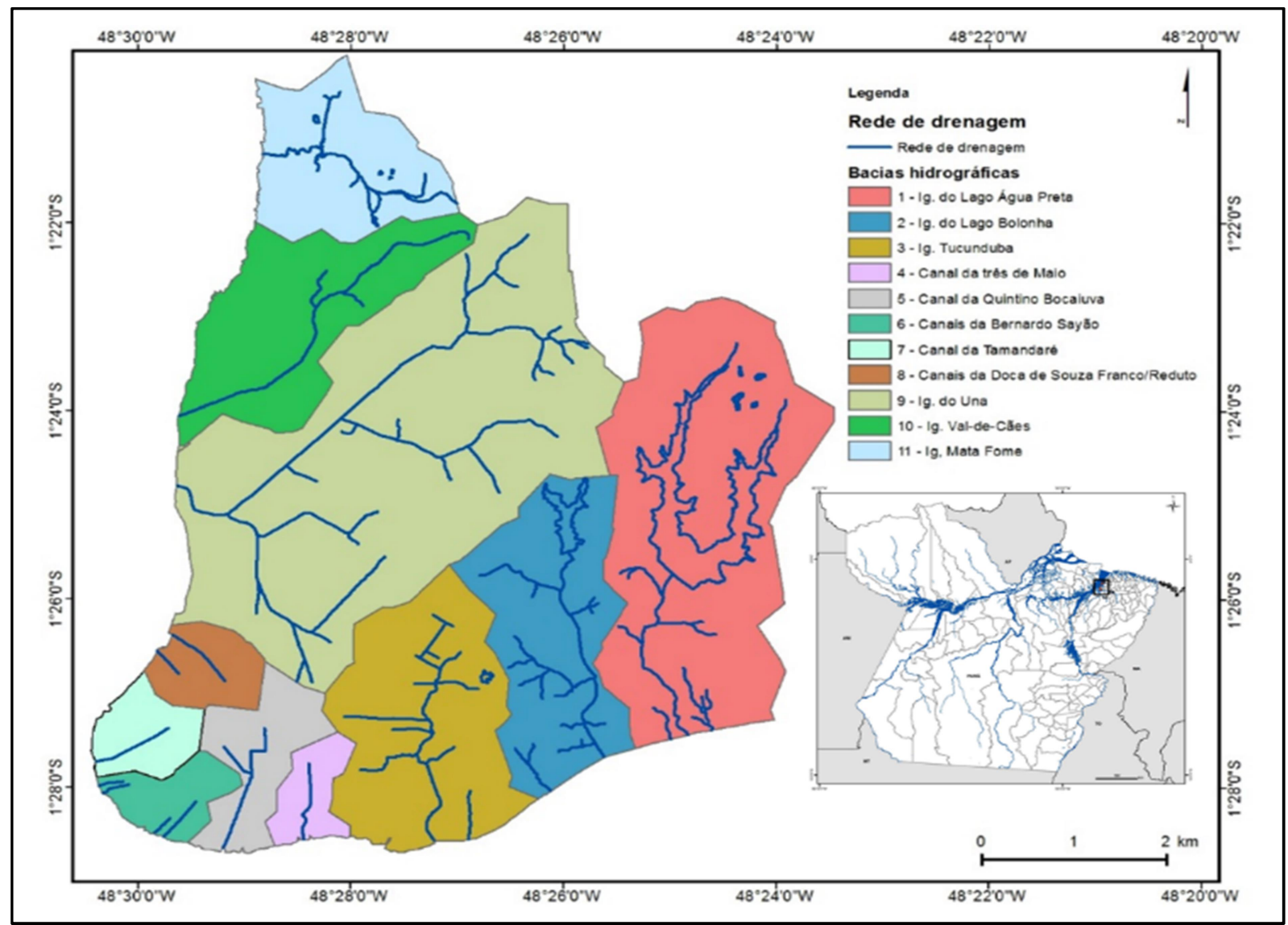

Fonte: Resultado de dados da pesquisa.

O bairro do Telégrafo Sem Fio, dentre outros de Belém, se organizavam de forma semelhante, uma vez que ocupavam espaços que tinham níveis topográficos que variavam de 5 a $10 \mathrm{~m}$, em encostas dos vales dos igarapés ou margem direita da baía de Guajará. Eram bairros residenciais com uma população pobre, que residiam em barracas, habitações construídas sobre estacas, algumas sujeitas às dinâmicas da maré e poucas casas de alvenaria, térreas ou assobradadas (Mapa 3) (PENTEADO, 1968). 
Mapa 3. Características da área de estudo

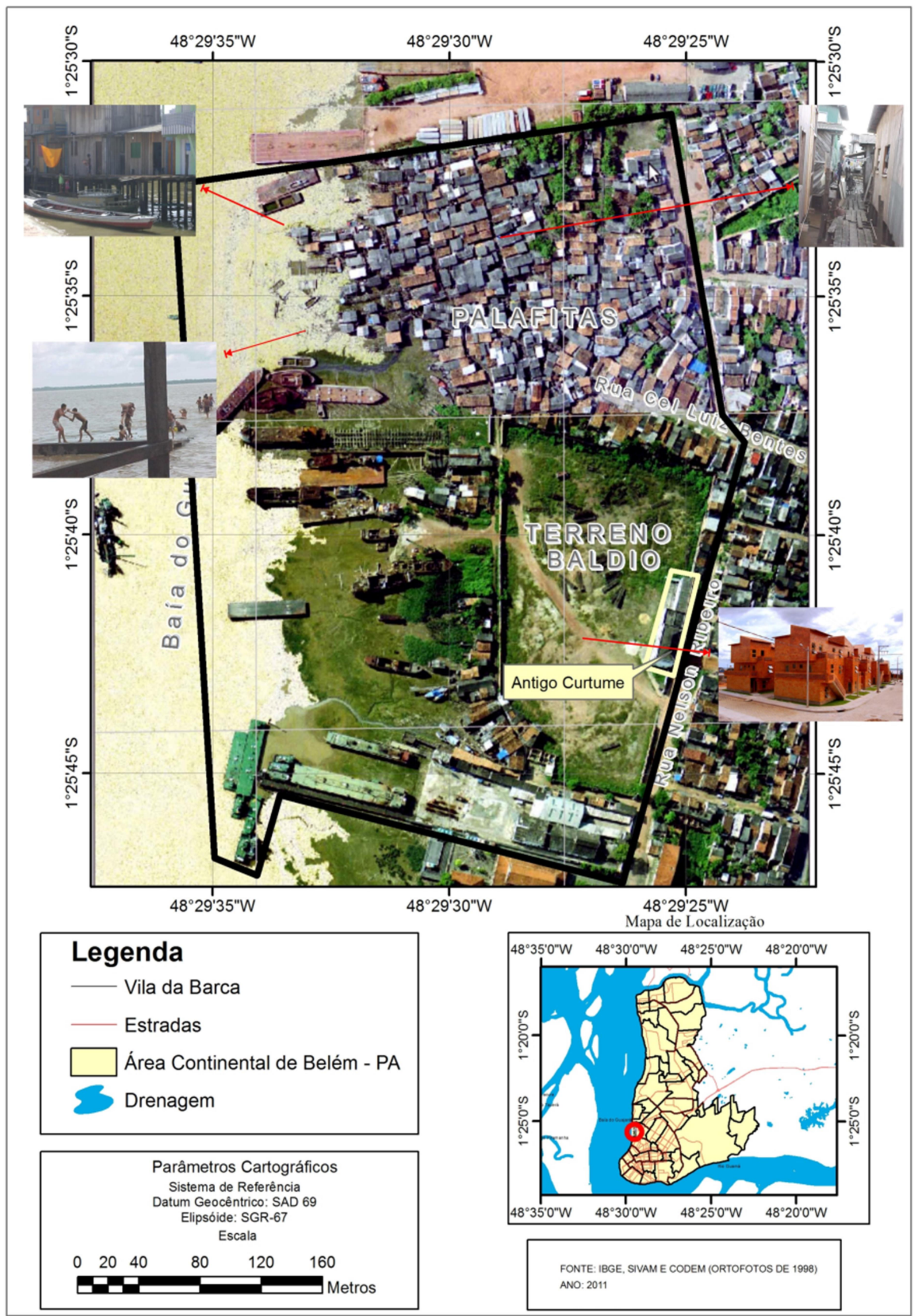

Fonte: Santos, 2012. 
A constituição histórica e geográfica de Belém se deu a partir de suas características ribeirinhas, onde os cursos d'água serviam como via, atrativo e campo de ação militar (SILVEIRA; BASSALO, 2012). Com o tempo, grande parte destes foram aterrados ou retificados em decorrência desse processo de ocupação urbana, perdendo com isso, sua importância social anterior, que era de lazer, retirada de recursos naturais para subsistência, tráfego, entre outros (SANTOS 2012).

Os canais afluentes do rio Guamá presentes em meio urbano, passaram a ser vistos como empecilhos ao processo de ocupação da área central de Belém, que se tornaram mais valorizadas em decorrência da concentração de serviços e da escassez de espaço nessa área (XIMENES, 2006). A política de aterramento vigente na cidade ocasionou a constante perda do equilíbrio do ecossistema urbano, uma vez que o próprio ambiente tem o seu "sistema de macrodrenagem" (rios, igarapés, córregos e lagos) de determinada parcela do solo, que respondem pelos movimentos cíclicos de enchentes e vazantes (PIMENTEL et al, 2012).

No processo de definição do modelo de percepção da paisagem foram adotadas 3 etapas:

1) levantamento da percepção socioambiental local por meio de entrevistas;

2) avaliação conceitual das intervenções sofridas;

3) aplicação da Análise Hierárquica (AHP), na avaliação das respostas obtidas.

$\mathrm{Na}$ análise da percepção ambiental e avaliação conceitual das intervenções, foram adotados os conceitos de topofilia e topofobia de Tuan (2012), o qual vem analisar a relação do sujeito com o lugar ou meio ambiente que este interage. Dessa forma, topofilia é entendido como o elo afetivo entre a pessoa e o lugar ou ambiente físico, vivido e concreto como experiência pessoal; e a topofobia como a relação negativa entre o sujeito e o lugar ou o meio que o cerca (SILVA, 2002; SILVA et al, 2014). Tendo em vista que esse conceito ressalta a insegurança que o indivíduo sente por algum motivo por estar inserido em determinado ambiente.

Para o teste da aplicação da AHP na avaliação da percepção social foram escolhidas 22 pessoas com o seguinte perfil quanto:

(a) ao sexo - 59,1\% masculino e 40,9\% feminino;

(b) a faixa etária - 31,8\% menor ou igual a 30 anos, 36,4\% de 30 anos a menor ou igual a 50 anos e $31,8 \%$ maior que 50 anos;

(c) a origem - $63,6 \%$ de Belém e $36,4 \%$ de outras localidades;

(d) a natureza da moradia - $63,6 \%$ em palafitas e $36,4 \%$ de alvenaria; 
(e) ao tipo de ocupação - 68,2\% com atividade externa e 31,8\% sem atividade (passa a maior parte do tempo em casa).

Com isso, objetivou-se agregar os principais perfis de moradores da região (SANTOS, 2012).A aplicação da AHP, de acordo com Silva et al (2006), tem quatro vantagens principais:

a) descreve como as mudanças em prioridades nos níveis mais altos afetam a prioridade dos níveis mais baixos;

b) os sistemas montados hierarquicamente desenvolvem-se mais eficientemente do que aqueles montados de um modo geral;

c) oferecem detalhes de informação sobre a estrutura e as funções de um sistema;

d) é estável porque pequenas modificações têm efeitos pequenos e flexível porque adições a uma hierarquia bem estruturada não perturbam o desempenho.

No emprego da AHP foi utilizado o software Expert Choice que executou uma análise hierárquica das categorias determinando o grau de importância a partir das variáveis consideradas. Tendo sido adaptada a sistematização de Marins et al (2006), onde inicialmente é definido o problema a ser tratado: a percepção da resposta socioambiental do processo de urbanização da orla de Belém. E a seguir os critérios a serem adotados:

(a) Tempo de residência no local - implica em avaliar o quanto este influencia no nível de resposta obtido, tendo sido dividido em 4 períodos: menor que 5 anos, de 5 a 20 anos, de mais de 20 anos até 50 anos e maior que 50 anos.

(b) Grau de satisfação com o projeto de urbanização - procura entender as relações das pessoas com seu ambiente geográfico, assim como sua relação com o espaço e o lugar, sendo classificado como: não satisfatório (NF), pouco satisfatório (PS), satisfatório (SF) e muito satisfatório (MS).

(c) Tipo de melhoria (qualidade de vida) que o projeto proporcionou - onde são identificados os elementos que significam em uma mudança positiva advinda do projeto, definidos pelas respostas obtidas pelos entrevistados: implantação de serviços de saneamento básico (SSB), construção de moradias mais seguras (ME), melhoria das condições de saúde (Sd), melhoria das condições de segurança (Sg), proporciona ambiente de lazer (Lz) e vias de acesso estruturadas (ruas) com pavimentação (VAE).

As respostas foram analisadas por meio de procedimentos de agregação e de classificação. O Quadro 1 resume as formas de agregação adotadas em função das relações obtidas. 
Quadro 1. Diagrama de relações adotado.

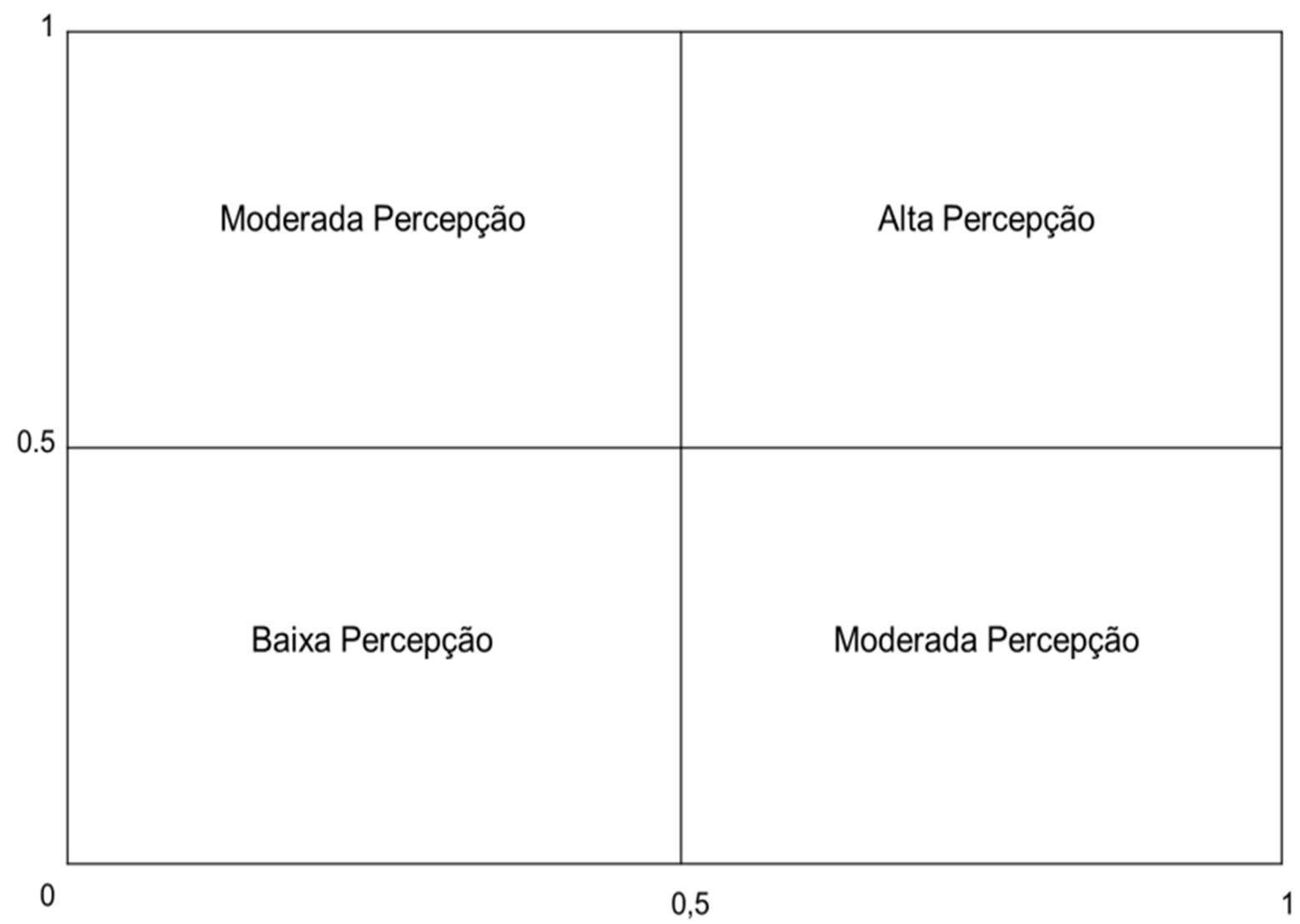

Fonte: Adaptado de Marins et al (2006) e Silva et al (2006).

\section{RESULTADOS E DISCUSSÃO}

\subsection{PERCEPÇÃO SOCIOAMBIENTAL}

Para entender as repostas do reordenamento da paisagem em função das intervenções de ordenamento do espaço urbano foi necessário uma análise da percepção destes sujeitos residentes na região; como estes sentem e compreendem a chegada desse novo elemento de atuação (ALVAREZ; MERINO, 2008).

Quanto ao perfil dos entrevistados, grande parte são nascidos em Belém, sendo seus pais, migrantes dos municípios do interior do Pará. O tempo de moradia dos entrevistados variou entre de menor que 4 anos à 71 anos de residência no bairro. Portanto, o maior tempo no local, configura uma percepção mais ampla sobre as transformações que ocorreram na paisagem (BARROS, 2006).

No contexto da topofilia, ou seja, os sentimentos positivos em relação ao lugar, o fator da localização geográfica da Vila da Barca, que está próximo ao centro da cidade, recebeu maior destaque. E isso é explicado pelo acesso aos serviços disponíveis na área central da 
cidade. Nota-se que fatores como segurança e tranquilidade foram mencionados e relacionados ao projeto de urbanização da vila.

A relação com a vizinhança, o lazer na beira do rio e os antigos banhos na maré foram lembrados como valores relevantes de convivência comunitária. Em decorrência dessas percepções que traduzem sentimentos positivos, nenhum dos entrevistados se imagina morando em outro lugar. Os moradores mais antigos mostram-se satisfeitos com os avanços infraestruturais, pois vivenciaram a chegada de alguns projetos, como o da substituição gradativa das habitações de palafitas.

Mas o sentimento de topofobia é um reflexo do longo período anterior de abandono do poder público em investimentos no local. A imagem negativa divulgada pela mídia explicitava, frequentemente, os casos de assassinatos, venda de drogas e furtos. Os programas de urbanização reduziram essas ocorrências, repercutindo no sentimento de segurança e tranquilidade, apresentados nos relatos para a pesquisa.

Representações da paisagem ribeirinha são recorrentes mostrando forte ligação com o rio, principalmente pelos que ainda estão nas palafitas, como local de lazer, onde tomam banho e se encontram com amigos. Tem ainda os moradores que desenvolvem atividades voltadas à pesca, que a tem como um auxílio a sua sobrevivência ou como subsistência nos momentos de desemprego.

\section{AVALIAÇÃO CONCEITUAL DO PROJETO DE URBANIZAÇÃO}

No contexto das reivindicações nas áreas de baixada, a comunidade da Vila da Barca, que vem se organizando há quase duas décadas através da Associação dos Moradores da Vila da Barca (AMVB), sempre buscou por meio de discussões e reivindicações perante o Estado, a construção de um projeto que visasse melhorar sua qualidade de vida, tendo em vista, sanar prioritariamente a ausência de alguns serviços básicos (SOUZA, 2006).

O Projeto de Habitação e Urbanização da Vila foi idealizado em 2000 e iniciou sua implantação em 2004. Ele foi fragmentado em três etapas, as quais, cada uma está inserida em programas como: Morar Melhor (concluído em 2007 com 136 unidades habitacionais), Palafita Zero (construção de 92 unidades habitacionais, incluindo elementos como: a mobilização e organização sócio-política, educação sanitária e ambiental e geração de trabalho e renda) e PAC (construção de 406 unidades habitacionais, com pavimentação, esgoto, drenagem e equipamentos urbanos). Para Baggio (2014) nas chamadas políticas de revitalização, se projetam interesses urbanísticos e territoriais de grande impacto, tanto na 
estrutura como na vida urbanas, tendo no capital imobiliário o vetor fundamental dessas frentes de expansão e valorização.

A percepção dos moradores sobre qualidade de vida, depois da implementação do projeto de urbanização, foi avaliada considerando: implantação de serviços de saneamento básico (SSB), construção de moradias mais seguras (ME), melhoria das condições de saúde (Sd), melhoria das condições de segurança $(\mathrm{Sg})$, criação de ambiente de lazer (Lz) e vias de acesso estruturadas (ruas) com pavimentação (VAE).

Os resultados destacam situações associadas à implantação dos elementos que compõem melhorias das condições de vida, como: os serviços de saneamento básico, realizado pela Estação de Tratamento de Esgoto (ETE); as moradias mais seguras, representadas pelo uso de alvenaria; a abertura de ruas e respectiva pavimentação; e a coleta de lixo. Outro fator, foram os serviços de segurança pública, com a maior presença de policiamento, decorrente do próprio processo de valorização da área.

Porém, foram percebidas situações associadas à falta de credibilidade dos moradores sobre o projeto, tais como: a qualidade das construções que apresentavam constantes rachaduras e infiltrações nas paredes dos apartamentos; além da falta de ventilação e desconforto térmico, dado pelo uso de materiais com capacidade de maior retenção de calor; e redução do espaço de convivência familiar em função do tamanho dos compartimentos.

Quando se discute a qualidade de vida, se abrange variados aspectos que perpassam por elementos materiais e elementos simbólicos, não estabelecendo qualquer ordem de superioridade entre ambas, se destacando, no entanto, a necessidade mais expressiva de cada grupo (VITTE, 2009).

Nessa análise da percepção da paisagem, que considera os seus aspectos socioambientais, são consequência da relação entre a sociedade e o ambiente, refletindo o uso dos recursos naturais utilizados para sua subsistência e as alterações das relações entre os sujeitos, de acordo com os seus interesses (AMORIM \& OLIVEIRA, 2008; TRES et al, 2011).

Ressalta-se que como objetivo específico do projeto de urbanização para a Vila da Barca, seria implementado um programa de educação ambiental, para melhorar as condições sanitárias e o uso adequado dos recursos naturais pela comunidade, como o uso das áreas de várzea. No entanto, essa pauta não foi atendida, ficando o projeto reduzido à construção das habitações, sem as demais ações complementares.

O estudo do processo de ocupação da Vila da Barca e da percepção ambiental dos moradores sobre as transformações ocorridas nesse espaço demonstrou a necessidade de uma 
leitura entre paisagem e território, constituindo uma análise integrada entre dinâmicas naturais, sociais e aspectos da política e da cultura (BERTRAND \& BERTRAND, 2009; GUERRA et al, 2012).

É pertinente refletir sobre o processo de degradação dos recursos naturais (sobretudo a ocupação das várzeas e o uso da água) e sobre as ações mitigadoras dos impactos sociais e ambientais decorrentes desses usos, desde investimentos mais adequados em infraestrutura urbana aos programas de educação ambiental (SILVA et al, 2012; PAULA et al, 2014).

Para a construção de tais projetos e programas, um elemento essencial é a sua discussão com os sujeitos que são diretamente afetados, e de forma consensual, elencar as principais necessidades dos moradores, fato que viria contribuir para a melhora de suas condições e qualidade de vida (TORRES et al, 2008; TRES et al, 2011).

Oportuno trazer nesse contexto de participação social o conceito de governança, como resultado da relação mais próxima entre sociedade civil organizada e Estado, para que ambos construam juntos Políticas Públicas voltadas à sociedade, uma vez que é esta última, que vive em seu cotidiano, as relações sociais e conhecem as condições ambientais adversas de sua moradia (VASCONCELLOS et al, 2009; RODRIGUES et al, 2012).

\section{APLICAÇÃO DA ANÁLISE HIERÁRQUICA}

Para AHP o problema associado foi "a percepção da resposta socioambiental do processo de urbanização da orla de Belém”. Os critérios adotados foram relativos aos fatores de: tempo de residência na área, grau de satisfação com o projeto de urbanização e o tipo de melhoria (qualidade de vida) que o projeto proporcionou.

O Gráfico 1 resume os resultados obtidos, onde nota-se que predominam moradores de 20 a 50 anos de moradia na área, que consideram pouco satisfatórias as melhorias obtidas e o que mais se destacou foram as mudanças na área do saneamento básico, associadas a coleta de resíduos sólidos e abastecimento de água.

O Gráfico 1. Apresenta estes critérios relativos: (a) Tempo de residência $(<5$ anos; 5 a 20 anos; 20 a 50 anos; > 50 anos); (b) Projeto de urbanização - não satisfatório (NF), pouco satisfatório (PS), satisfatório (SF) e muito satisfatório (MS); (c) Tipo de melhoria (qualidade de vida): serviços de saneamento básico (SSB), moradias mais seguras (ME), condições de saúde $(\mathrm{Sd})$, condições de segurança $(\mathrm{Sg})$, ambiente de lazer $(\mathrm{Lz})$ e vias de acesso estruturadas (VAE). 
Gráfico 1. Critérios adotados relativos:

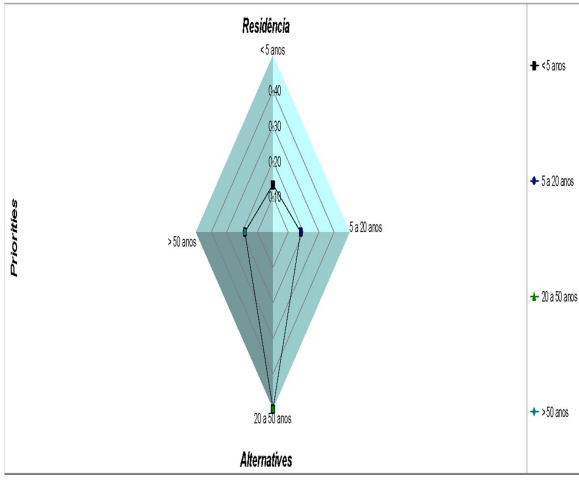

Fonte: Resultado de dados da pesquisa.

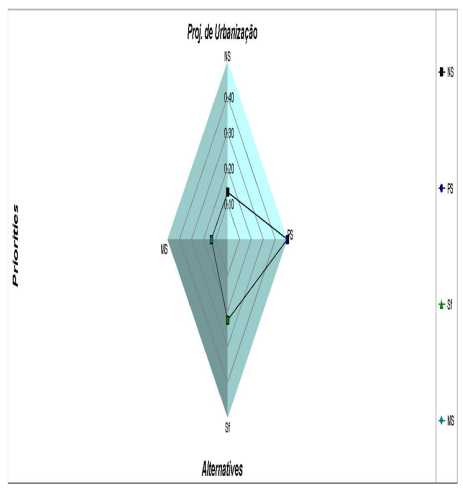

(b)

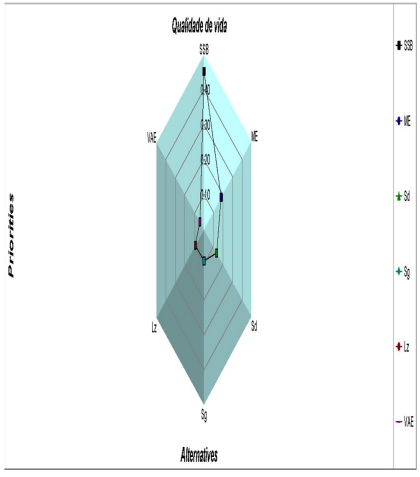

(c)

A Figura 1 demonstra as relações de percepção obtidas entre: tempo de residência na área $\mathrm{x}$, grau de satisfação com o projeto de urbanização x, o tipo de melhoria (qualidade de vida) que o projeto proporcionou; e o tipo de melhoria (qualidade de vida) que o projeto proporcionou x o grau de satisfação com o projeto de urbanização.

Figura 1. Relações de percepção obtidas

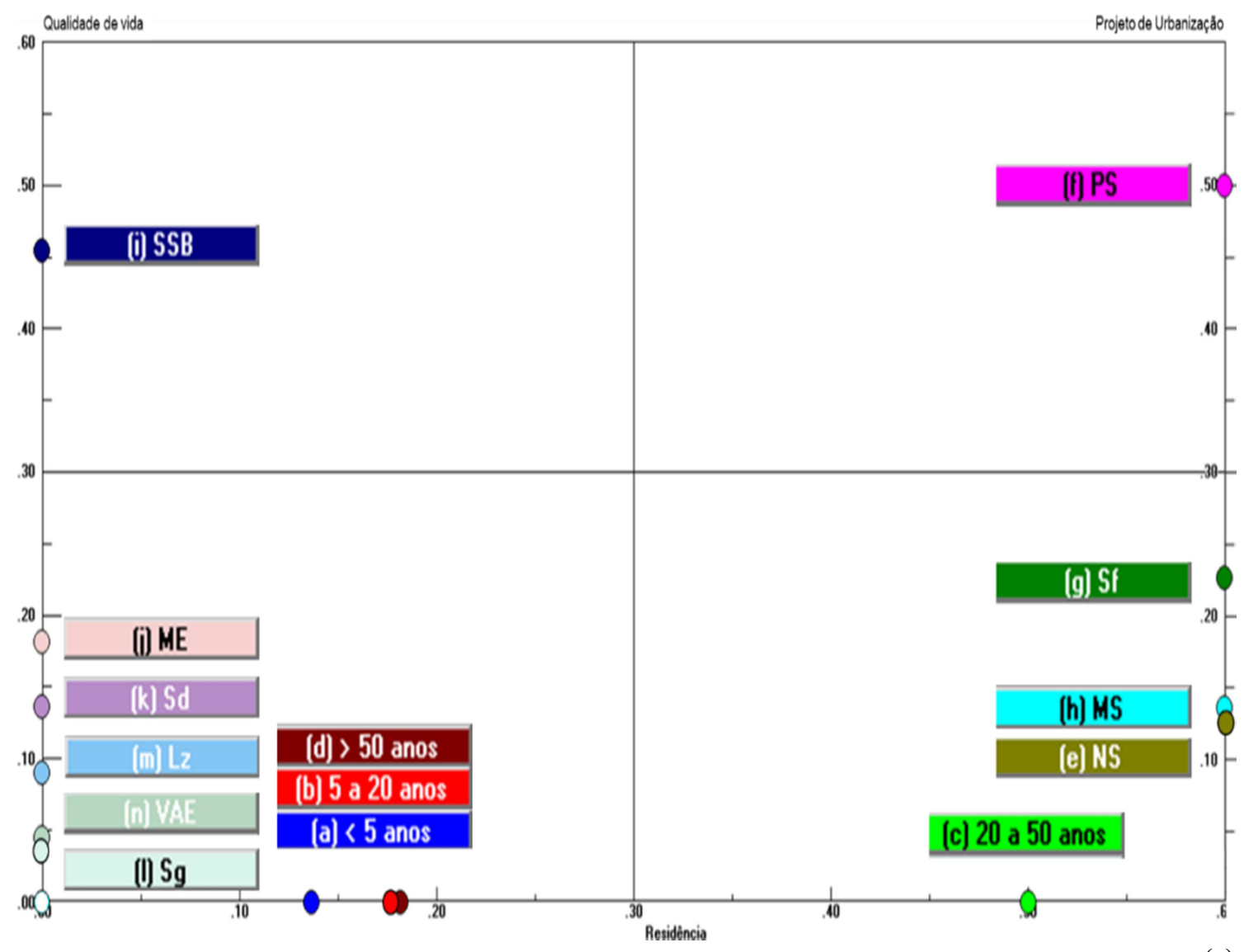

(a) 


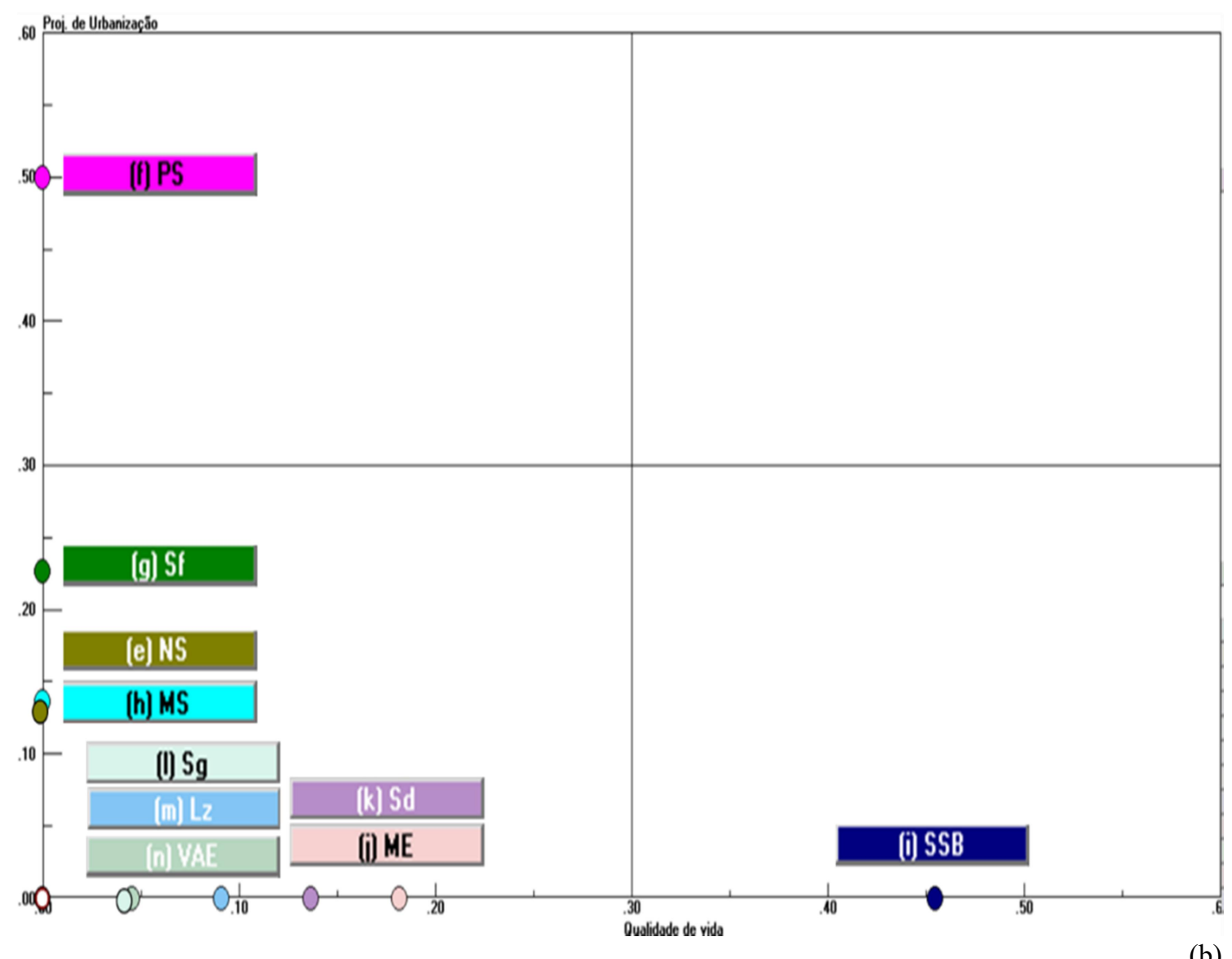

Fonte: Resultado de dados da pesquisa.

(b)

O Tempo de residência $<5$ anos, 5 a 20 anos e $>50$ anos apresentou uma baixa relação (Figura 1a) com a compreensão do projeto de urbanização considerada não satisfatório (NS), satisfatório (SF) e muito satisfatório (MS); e com o tipo de melhoria as moradias mais seguras (ME), condições de saúde (Sd), ambiente de lazer (Lz) e vias de acesso estruturadas (VAE). Uma moderada com a avaliação pouco satisfatório (PS) e com os serviços de saneamento básico (SSB).

A faixa de 20 a 50 anos teve uma moderada relação com a percepção do projeto de urbanização considerada não satisfatório (NS), satisfatório (SF) e muito satisfatório (MS); entendendo como melhoria as moradias mais seguras (ME), condições de saúde ( $\mathrm{Sd}$ ), ambiente de lazer (Lz) e vias de acesso estruturadas (VAE). E alta com a avaliação pouco satisfatório (PS) dos serviços de saneamento básico (SSB). Ou seja, as melhorias induzidas pelo saneamento básico não atenderam às expectativas locais, tendo alta percepção pouco satisfatória e moderada como uma ação que pode ser considerada na média como satisfatória (Figura 1b).

As demais ações que implicam em uma melhoria do ambiente tiveram uma baixa à moderada percepção. Tais resultados indicam que pelo grupo entrevistado, o empreendimento 
não está atendendo ao esperado ou suas ações não estão sendo apresentadas à comunidade, de forma a esclarecer corretamente os seus benefícios.

Quando eliminada a dispersão observada nos campos de "Moderada Percepção" e observa-se, como ilustrado no mapa cognitivo da Figura 2, que existe uma definição clara da linha de Alta Percepção ligando o "Pouco Satisfatório" as condições de "Saneamento". E uma indecisão quanto das demais categorias, no campo da "Baixa Percepção".

Figura 2. Mapa cognitivo com os campos extremos: alta e baixa percepção

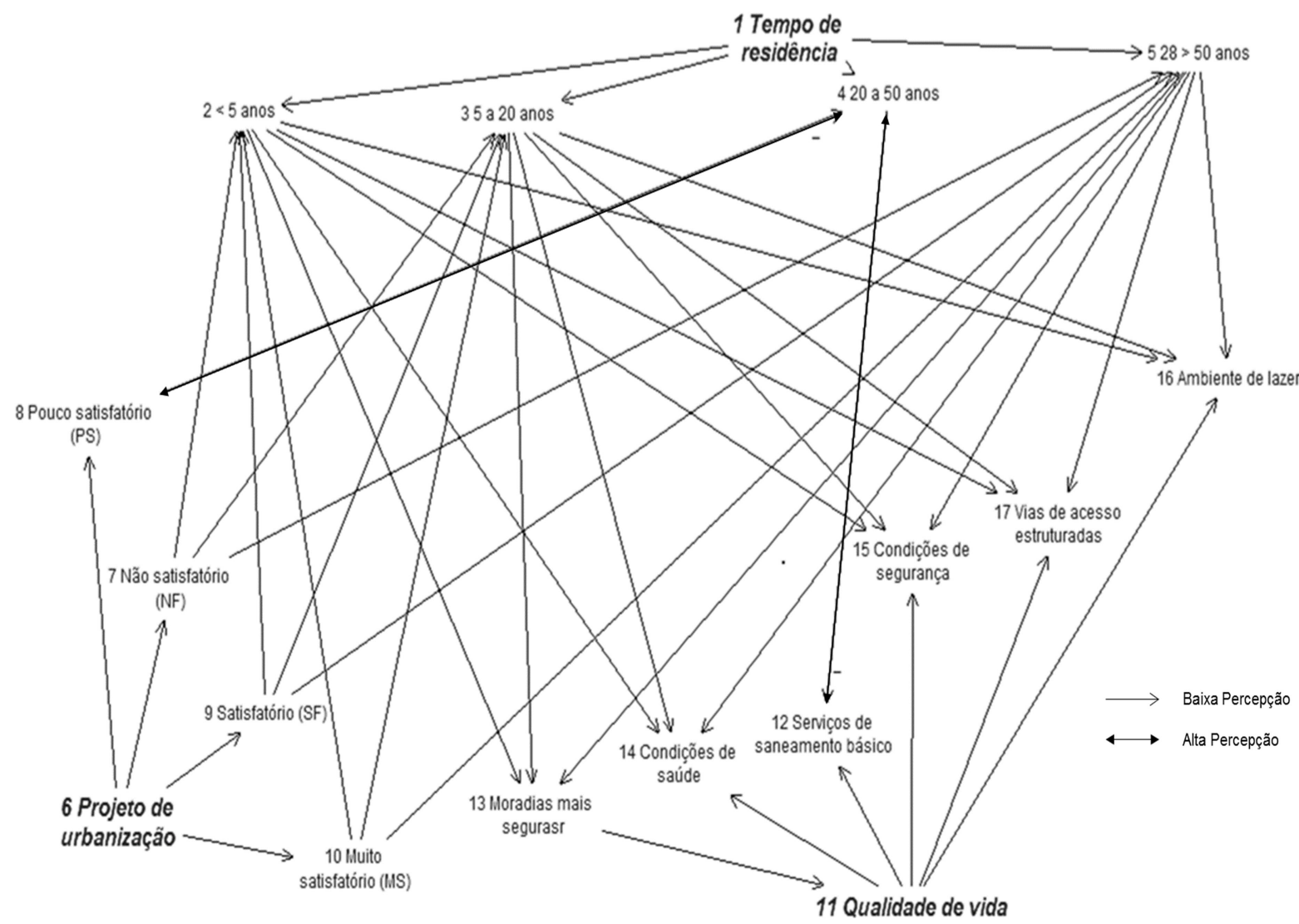

Fonte: Dados da pesquisa

A demanda por infraestrutura urbana é um elemento de destaque vinculado a noção de qualidade de vida (RODRIGUES et al, 2012; SAMPAIO et al, 2012), mesmo em situações onde o ambiente natural (como é o caso dos ambientes de várzea) tem a vocação de ser destinado a conservação. Situações naturais como a ocorrência sazonal de cheias, passam a se tornar uma ameaça, definindo estas áreas como de risco a ocorrência de inundações. Neste momento, a ideia central é que a inundação torna-se o problema e não a opção por moradia na várzea (GORAYEB et al, 2009; CARNEIRO et al, 2010). 
O comportamento difuso do mapeamento realizado, com uma grande quantidade de variáveis nos campos de "Baixa e Moderada Percepção" e com a pouca indicação de segmentos bem definidos, ilustra que a inserção socioambiental do projeto, segundo o grupo amostrado, é fraca. O que amplia a vulnerabilidade socioambiental da área, uma vez que as mudanças efetivadas não foram completamente internalizadas de forma física e conceitualmente. Com essas áreas sendo incorporadas sob o ponto de vista da necessidade de espaço, tendo o seu consumo erroneamente valorizado (RESENDE, 2013).

O ambiente percebido, segundo o mapeamento realizado, representa um exemplo das relações de ocupação urbana em regiões metropolitanas. Nestes espaços, as relações são influenciadas pelos pacotes tecnológicos que desempenham um papel importante, onde a cidade não surge de uma atividade produtiva própria, ela evolui e se desenvolve pouco a pouco (WANDSCHEER et al, 2012); com a entrada dos habitantes migrantes de outros meios, como o rural, traduzindo em formas de ocupação vinculadas ao preenchimento de espaços "vazios" ou de qualidade de vida insatisfatória.

A melhor solução seria a execução de propostas de zoneamento com a identificação e delimitação de situações ambientais com diferentes características, que passariam a ser definidas com o objetivo de delimitar unidades de planejamento, a partir de abordagens vinculadas a gestão das classes de uso/ocupação do solo, observando-se as características ambientais de cada tipo de ocupação (ARAGÃO et al, 2014).

\section{CONCLUSÃO}

As alterações geradas na paisagem a partir da tentativa de ajuste do ambiente instalado, de ocupação irregular de áreas de várzea, por meio de um projeto de urbanização em uma área situada na bacia do Una (Vila da Barca, Belém-PA) teve como premissa, a melhoria da qualidade de vida desses moradores. Porém, o mapeamento realizado observou que seus resultados não foram percebidos, como esperado, na comunidade local.

A urbanização de ambientes naturais deve considerar o processo de construção histórica de uma região, que tem um significado que vai para além de um lugar com função de moradia para a comunidade envolvida. Mais que isso, sua paisagem expressa todo um significado social que só é sentido por aqueles que a vivem e tem sua história como herança de vida.

As ações de gestão e planejamento ambiental devem ser incorporadas nesta lógica, devendo-se questionar até que ponto a manutenção de determinadas condições não amplia as condições de vulnerabilidade socioambiental de uma comunidade; ou qual o investimento de 
infraestrutura realmente necessário para adequação de determinada comunidade ao ambiente em que ela está inserida.

Belém é uma cidade intensamente drenada com bacias urbanas, onde as áreas de várzea representam espaços que devem ter propostas diferenciais, com planos de urbanização específicos para as suas necessidades, adequando tanto das demandas sociais de infraestrutura, aos aspectos naturais que condicionam sua dinâmica, minimizando assim os impactos sobre os sistemas fluviais existentes.

\section{REFERENCIAS}

AMORIM, R. R.; OLIVEIRA, R. C. As unidades de paisagem como uma categoria de análise geográfica: o exemplo do município de São Vicente-SP. Sociedade \& Natureza, v. 20, n. 2, p. 177-198, 2008.

ARAGÃO, A. K. O.; AlOUFA, M. A. I.; CAVAlCANTE, J. S. I.; COSTA, D. F. S. Zoneamento ambiental como instrumento estratégico para a gestão municipal na microrregião do Vale do Açu (RN). Geografia, v. 23, n. 2, p. 95-112, 2014.

BAGGIO, U. C. A metrópole sob a perspectiva da alienação e da apropriação de espaços: incursões pelo centro antigo de São Paulo. Rev. do Departamento de Geografia, v. 28, p. 157-179, 2014.

BARROS, J. A. História, espaço e tempo: interações necessárias. Varia Historia, v. 22, n. 36, p. 460-475, 2006.

BERTRAND, G.; BERTRAND C. Uma Geografia transversal e de travessias: o meio ambiente através dos territórios e das temporalidades. Maringá: Massoni, 2009, 332p.

CARNEIRO, P. R. F.; CARDOSO, A. L.; ZAMPRONIO, G. B.; MARTINGIL, M. C. A gestão integrada de recursos hídricos e do uso do solo em bacias urbano-metropolitanas: o controle de inundações na bacia dos Rios Iguaçu/Sarapuí, na Baixada Fluminense. Ambiente \& Sociedade, v. 13, n. 1, p. 29-49, 2010.

DIAS V. S. B.; SILVA A. B. AHP na modelagem da vulnerabilidade ambiental do mini corredor ecológico Serra Das Onças (BA). Rev. Brasileira de Cartografia, v. 66, n. 6, p. 1363-1377, 2014.

FERREIRA, V. O. A abordagem da paisagem no âmbito dos estudos ambientais integrados. GeoTextos, v. 6, n. 2, p.1 87-208, 2010.

GORAYEB, A.; LOMBARDO, M. A.; PEREIRA, L. C. C. Condições ambientais em áreas urbanas da bacia hidrográfica do rio Caeté, Amazônia Oriental, Brasil. Rev. da Gestão Costeira Integrada, v. 9, n. 2, p. 59-70, 2009. 
GUERRA, M. D. F.; SOUZA, M. J. N.; LUSTOSA, J. P. G. Revisitando a teoria geossistêmica de Bertrand no século XXI: aportes para o GTP (?). Geografia em Questão, v. 5, n. 2, p. 28-42, 2012.

KENYON, W. Evaluating flood risk management options in Scotland: a participant-led multi-criteria approach. Journal of Ecological Economics, v. 64, p. 70-81, 2007.

MARINS, C. S.; SOUZA, D. O.; FREITAS, A. L. P. A metodologia de multicritério como ferramenta para a tomada de decisões gerenciais: um estudo de caso. GEPROS, n. 2, p. 51-60, 2006.

MATEO RODRIGUEZ, J. M.; SILVA, E. V. La geoecologia del paisaje como fundamento para el análisis ambiental. REDE - Rev. Eletrônica do Prodema, v. 1, n. 1, p. 77-98, 2007.

MATOS, F. C.; TARGA, M. S.; BATISTA, G. T.; DIAS, N. W. Análise temporal da expansão urbana no entorno do Igarapé Tucunduba, Belém, PA, Brasil. Rev. Biociências, v. 17, n. 1, p. 7-16, 2011.

MERWADE, V.; OLIVERA, F.; ARABI, M.; EDLEMAN, S. Uncertainty in flood inundation mapping: current issues and future directions. Journal of Hydrologic Engineering, v. 13, n. 7, p. 608-620, 2008.

MEZZOMO, M. D. M. Considerações sobre o termo "paisagem" segundo o enfoque Geoecológico. In: NUCCI, João C. (Org.) Planejamento da Paisagem como subsídio para a participação popular no desenvolvimento urbano. Curitiba: LABS/DGEOG/UFPR, 2010, $277 \mathrm{p}$.

MORAES, R. P.; CARVALHO, T. M. Cobertura da terra e parâmetros da paisagem no munícipio de Caracaraí - Roraima. Rev. Geográfica Acadêmica, v. 7, n. 1, p. 46-59, 2013.

PAUlA, E. M. S.; SILVA, E. V.; GORAYEB, A. Percepção ambiental e dinâmica geoecológica: premissas para o planejamento e gestão ambiental. Sociedade \& Natureza, v. 26, n. 3, p. 511-518, 2014.

PIMENTEL, M. A. S.; SANTOS, V. C.; SIlVA, F. A. O.; GONÇALVES, A. C. A ocupação das várzeas na cidade de Belém: causas e consequências socioambientais. Rev. Geonorte, v. 2, n. 4, p. 34-45, 2012.

RESENDE, U. P. Especulação imobiliária e verticalização urbana: um estudo a partir do Parque Municipal Cascavel em Goiânia. Geografia, v. 22, n. 2, p. 79-102, 2013.

RIBEIRO, W. C. Impactos das mudanças climáticas em cidades no Brasil. Parcerias Estratégicas, n. 27, p. 297-321, 2008.

RODRIGUES, M. L.; MALHEIROS, T. F.; FERNANDES, V.; DAGOSTIN DAROS, T. A percepção ambiental como instrumento de apoio na gestão e na formulação de políticas públicas ambientais. Saúde e Sociedade, v. 21, n. 3, p. 96-110, 2012. 
SAMPAIO, S. F.; DELLA JUSTINA, E. E.; BEZERRA, S. F.; ARAÚJO, M. S. Características socioeconômicas dos moradores de área de risco da bacia do igarapé Grande- Porto Velho (RO). Rev. Geonorte, v. 1, n. 4, p. 501-514, 2012.

SANTOS, Viviane Corrêa. Requalificação urbana da paisagem de várzea da Vila da Barca - Belém/Pará e suas consequências. 2012. 131f. Dissertação (Mestrado em Geografia) - Instituto de Filosofia e Ciências Humanas, Universidade Federal do Pará, Belém, 2012.

SANTOS ALVAREZ, M. V.; GARCIA MERINO, M. T. Environmental uncertainty: the side object of perception. Innovar, v. 18, n. 32, p. 65-74, 2008.

SILVA, C. A. O turismo no contexto da Geografia Humanística: espaço e lugar. Boletim Goiano de Geografia, v. 22, n. 2, p. 73-92, 2002.

SILVA, E. F.; COSTA, E. M. A.; MOURA, G. J. B. Topofobia e topofilia em "A Terra", de "Os Sertões": uma análise ecocrítica do espaço Sertanejo Euclidiano. Sociedade \& Natureza, v. 26, n. 2, p. 253-260, 2014.

SILVA, J. T. M.; CABRERA, P. A. L.; TEIXEIRA, L. A. A. Aplicação do método de análise hierárquica no processo de tomada de decisão: um estudo com o empreendedor agrícola da região de Divino/MG. Rev. Gestão e Planejamento, v. 7, n. 14, p. 19-30, 2006.

SILVA. E. V. Geografia Física, geoecologia da paisagem e educação ambiental aplicada: interações interdisciplinares na gestão territorial. Rev. Geonorte. v. 4, n. 4, p. 175-183, 2012.

SILVEIRA; F. L. A.; BASSALO, T. F. R. Corpos em equilíbrio: imagens e cotidiano ribeirinho no porto do Açaí e na ilha do Maracujá, Belém (PA). História, Ciências, SaúdeManguinhos, v. 19, n. 3, p. 1049-1073, 2012.

SOUZA, Solange Silva. Os Caminhos da urbanização da Vila da Barca: passado, presente e perspectivas futuras. 2006. 130f. Dissertação (Mestrado em Serviço Social) - Centro Socioeconômico, Universidade Federal do Pará, Belém, 2006.

SOUZA, T. A.; CUNHA, C. M. L. Representação da paisagem através da carta de unidades geoambientais em áreas litorâneas. Mercator, v. 13, n. 3, p. 105-119, 2014

TARGA, M. S.; BATISTA, G. T.; DINIZ, H. D.; DIAS, N. W.; MATOS, F. C. Urbanização e escoamento superficial na bacia hidrográfica do Igarapé Tucunduba, Belém, PA, Brasil. Ambi-Agua, v. 7, n. 2, p. 120-142, 2012.

TORRES, D. F; OLIVEIRA E. S. Percepção Ambiental: instrumento para educação ambiental em unidades de conservação. Rev. Eletrônica Mestr. Educ. Ambiental, v. 21, p. 1517-1256, 2008.

TRES, D. R.; REIS, A.; SCHLINDWEIN, S. L. A construção de cenários da relação homem-natureza sob uma perspectiva sistêmica para o estudo da paisagem em fazendas produtoras de madeira no planalto norte catarinense. Ambiente \& Sociedade, v. 14, n. 1, p. 151-173, 2011. 
TUAN, Yi-Fu. Topofilia: um estudo da percepção, atitudes e valores do meio ambiente. Londrina: Eduel, 2012, 342p.

VASCONCELlOS, M.; VASCONCELlOS, A. M. A.; SOUZA, C. A. Participação e governança urbana. In: VASCONCELLOS, M.; ROCHA, G. M.; LADISLAU, E. (Org.). Desafios políticos da sustentabilidade urbana. Belém: NUMA/UFPA, 2009, 179p.

VESTENA, L.; GEFFER, E.; ALMEIDA, D. E. F.; VESTENA, C. L. B. Percepção ambiental sobre as causas das inundações, Guarapuava/PR: em busca da cidade resiliente. Rev. do Departamento de Geografia, v. 28, p. 280-294, 2014.

VITTE, C. C. S. A qualidade de vida urbana e sua dimensão subjetiva: uma contribuição ao debate sobre políticas públicas e sobre a cidade. In: VITTE, C. C. S.; KEINERT, T. M. M. (Org.) Qualidade de vida, planejamento e gestão urbana: discussões teóricometodológicas. Rio de Janeiro: Bertrand Brasil, 2009, 312p.

WANDSCHEER, E. A. R.; DUTRA, E. J. S.; FONTOURA, L. F. M. A relação entre o rural e o urbano: transformações e dinâmica na formação espaço-temporal de Canguçu e Horizontina, Rio Grande do Sul, Brasil. Geografia, v. 21, n. 1, p. 163-183, 2012.

XIMENES, J. Cidade e água: Belém do Pará e estratégias de reapropriação das margens fluviais. Arquitextos, v. 085, p. 2, 2007.

XIMENES, J. Sustentabilidade, desenvolvimento e planejamento urbano -reconfiguração de margens fluviais em Belém (PA). Rev. Brasileira de Estudos Urbanos e Regionais, v. 8, p. 27-44, 2006. 